\title{
Variable seasonal coupling between air and ground temperatures: A simple representation in terms of subsurface thermal diffusivity
}

\author{
Henry N. Pollack, Jason E. Smerdon, and Peter E. van Keken \\ Department of Geological Sciences, University of Michigan, Ann Arbor, Michigan, USA \\ Received 20 June 2005; accepted 7 July 2005; published 11 August 2005.
}

[1] The utility of subsurface temperatures as indicators of temperature changes at Earth's surface rests upon an assumption of strong coupling between surface air temperature (SAT) and ground surface temperature (GST). Here we describe a simple representation of this coupling in terms of a variable thermal diffusivity in the upper meter of the subsurface. The variability is tied to daily SAT, precipitation, and snow cover, but does not incorporate the physical details of these and the many other factors that influence the air-ground interface in many high-fidelity landsurface models. Our simple model reduces the difference between observed and modeled temperatures by a factor of 3 to 4 over a model with uniform diffusivity driven only by SAT. This simple representation of air-ground coupling offers a means of simulating subsurface temperatures using only archived meteorological records and creates the potential for examining the long term character of air-ground temperature coupling. Citation: Pollack, H. N., J. E. Smerdon, and P. E. van Keken (2005), Variable seasonal coupling between air and ground temperatures: A simple representation in terms of subsurface thermal diffusivity, Geophys. Res. Lett., 32, L15405, doi:10.1029/ 2005 GL023869.

\section{Introduction}

[2] Present-day subsurface temperature profiles can be inverted to reconstruct temperature histories at the ground surface that span many centuries. These ground surface temperature (GST) histories in turn are used to estimate surface air temperature (SAT) changes at times prior to the beginning of the instrumental record. Implicit in the latter undertaking is the assumption that SAT and GST are closely coupled at long timescales. This assumption has been the subject of some discussion [González-Rouco et al., 2003; Mann and Schmidt, 2003; Chapman et al., 2004; Pollack and Smerdon, 2004]. The discussion arises because of known differences between SAT and GST over much shorter periods (daily and seasonal) caused by, inter alia, the effects of snow cover, ground freezing and thawing, and evapotranspiration [Schmidt et al., 2001; Zhang et al., 2001; Baker and Baker, 2002; Osterkamp, 2002; Sokratov and Barry, 2002; Stieglitz et al., 2003; Bartlett et al., 2004; Grundstein et al., 2005].

[3] Meteorological effects have been shown to cause the amplitude of the annual cycle in ground temperatures to be less than the annual cycle in air temperatures (J. E. Smerdon et al., Daily, seasonal and annual relationships between air and subsurface temperatures, submitted to Journal of
Geophysical Research, 2005, hereinafter referred to as Smerdon et al., submitted manuscript, 2005). Thus shallow subsurface temperature variations are effectively a muted version of air temperature variations, and usually have a different annual mean. Smerdon et al. [2004, also submitted manuscript, 2005] illustrate these effects at four sites that are climatologically quite different: Fargo, North Dakota; Cape Henlopen, Delaware; Cape Hatteras, North Carolina; and Prague, Czech Republic. Fargo shows a mean annual GST warmer than the SAT, the two Capes show GST annual means cooler than the SAT, and Prague shows mean annual GST and SAT to be almost the same. While these differences are apparent on annual timescales, neither different annual amplitudes nor different annual means invalidate the assumption that air and ground temperatures track each other over long timescales. Only if differences between mean annual air and shallow subsurface temperatures change systematically over long times and large regions would GST reconstructions lose credibility as estimates of changes in SAT. It is therefore necessary to investigate the effects of annual differences between GST and SAT on the long-term relationships between the two temperatures.

[4] Here we outline and test a method for modeling subsurface temperatures by taking into account the day-today effects of meteorological conditions. We model meteorological influences on subsurface temperatures by capping the subsurface with a thin $(<1 \mathrm{~m})$ surficial layer that is characterized by a time-dependent thermal diffusivity controlled by the meteorological conditions. The thermal diffusivity, defined as the ratio of the thermal conductivity to the volumetric heat capacity, is affected by the common meteorological factors: snow cover is equivalent to a reduction of the thermal conductivity, and latent heat effects associated with freezing, thawing and evapotranspiration are equivalent to an increase of the volumetric heat capacity. Thus all of these meteorological effects can be simply represented in a single thermophysical property, the thermal diffusivity of the shallow subsurface, and modeled by reducing the diffusivity in this surficial zone by empirically determined amounts related to winter insulation and year-round latent heat effects.

\section{Models}

[5] We calculate subsurface temperatures under the assumption of conductive heat transfer driven by a timedependent surface boundary condition set equal to the SAT. We solve the one-dimensional heat conduction equation using central finite differences for the spatial coordinate and integration of the resulting set of ordinary 
differential equations using the solver DASPK ([Brown et al., 1994] http://www.engineering.ucsb.edu/ cse/software. html). DASPK employs a predictor-corrector method using backward difference formulas up to order five. The method is adaptive with self-selecting time-step and integration order that are based on user-specified error tolerances. An example of the use of DASPK to model mantle convection is given by van Keken et al. [1995]. We employ this formalism to model subsurface temperatures as a function of time, driven by (coupled to) a time-dependent upper boundary condition equal to the SAT. This formalism accommodates both of the model scenarios we describe below.

[6] The first model we consider (Model I) is simply a half-space with a temporally and spatially uniform thermal diffusivity. This model serves as a straw-man model to which we compare the results of a second model (Model II) that is characterized by a time-dependent thermal diffusivity in a thin superficial layer. The first model is a 'perfectly coupled' model in which subsurface temperatures are driven directly by the SAT at the surface boundary. The second is an 'imperfectly coupled' model, in which temperatures beneath the thin surficial layer are driven by the altered signal that has passed through the layer.

[7] In the thin upper layer of Model II, the diffusivity is selectively reduced according to daily values of mean SAT, precipitation, and snow cover, all routinely archived meteorological quantities. Reduction of the thermal diffusivity occurs on any day that there is rainfall or snow cover, or when the mean daily SAT is at or below $0^{\circ} \mathrm{C}$. The amount of the reduction in thermal diffusivity and the thickness of the variable diffusivity layer are parameters of the numerical model that we attempt to optimize. Below the upper layer of variable diffusivity, the model comprises a semi-infinite medium with uniform diffusivity.

[8] We test the two models by comparing modeled subsurface temperatures to observed subsurface temperatures collected at the North Dakota State University Microclimate Research Station $\left(46^{\circ} 54^{\prime} \mathrm{N}, 96^{\circ} 48^{\prime} \mathrm{W}\right)$ in Fargo, North Dakota. This station has measured air and subsurface temperatures hourly, and recorded precipitation and snow cover daily, for more than two decades. Subsurface temperatures are recorded at 22 depths between the surface and $11.7 \mathrm{~m}$, with ten closely spaced sensors in the upper meter alone. The site and data acquisition are described by Schmidt et al. [2001]. We select the years May 1981-April 1982 and May 1982-April 1983, two very different meteorological years at the site, for parameter optimization. The first year was one of significant snow cover, whereas the second year experienced a warmer winter with little snow cover. We partition the calendar years to capture a full summer and full winter in a single twelve month period.

[9] We tune Model II by sweeping through the parameter space of factors affecting the reduction of thermal diffusivity, and calculating the differences between observed and modeled temperatures to determine which combination of factors yield minimum differences. One parameter is the thickness of the layer in which thermal diffusivity is altered. We investigate thicknesses between $10 \mathrm{~cm}$ and $1 \mathrm{~m}$, in increments of $10 \mathrm{~cm}$. Confining meteorological influences to the upper meter of the subsurface is supported by the observation of Smerdon et al. [2003] that both the thermal diffusivity and the velocity of the annual thermal wave at Fargo, a site that experiences a full range of seasonal effects, increases downward through the upper meter of soil, reaching a value that is more or less uniform at greater depths. Similarly, at higher latitudes, the active layer in permafrost is typically less than one meter [Hinkel and Nelson, 2003].

[10] A second parameter is the factor by which the thermal diffusivity in the upper layer is reduced from its nominal value on days when snow cover is present or the surface air temperature is below $0^{\circ} \mathrm{C}$; we investigate reduction factors ranging from zero to $90 \%$, in increments of $10 \%$. A third parameter, the factor by which the thermal diffusivity in the upper layer is reduced on days when precipitation is recorded and the surface air temperature is above $0^{\circ} \mathrm{C}$, ranges from zero to $30 \%$. The diffusivity of the underlying half-space is maintained at the constant value of $3.7 \pm 0.1 \times 10^{-7} \mathrm{~m}^{2} \mathrm{~s}^{-1}$, as determined by Smerdon et al. [2003]. This value is also used in the upper layer when none of the above criteria for a diffusivity reduction are met. Because the amount of snow is so different in the two observational years, we investigate and optimize the parameters for each year separately, to explore the range of optimized parameters.

\section{Results}

[11] To quantify the performance of the two models in each of the two tuning years, we determine the minimum RMS residuals between the observed and modeled temperatures at all depths $1 \mathrm{~m}$ and below. For Model I these residuals were $3.7^{\circ} \mathrm{C}$ and $2.7^{\circ} \mathrm{C}$ during the $1981-82$ and 1982-83 years, respectively. Model II performed significantly better than Model I; the minimum RMS residuals during the 1981-82 and 1982-83 years using Model II were $0.51^{\circ} \mathrm{C}$ and $0.56^{\circ} \mathrm{C}$ (improvements by factors of about 7 and 5), respectively. These optimal results correspond to a winter reduction of thermal diffusivity in the range of $80-$ $90 \%$, a depth of diffusivity reduction in the range of $0.3-$ $0.4 \mathrm{~m}$, and summer reductions of thermal diffusivity in the range $0-20 \%$. Using the mean of each parameter for both observational years $(85 \%, 0.35 \mathrm{~m}, 10 \%$, respectively) we achieve an RMS residual of $0.67^{\circ} \mathrm{C}$ over the entire two-year observational period.

[12] The results of these computations are graphically compared in Figures 1a-1f, with the left and right columns representing the two observational years (1981-82 and 1982-83), respectively. Observed precipitation and snow cover are displayed in Figure 1a; total precipitation was around $50 \mathrm{~cm}$ in both years, but much more fell as snow in 1981-82. In the winter of 1981-82 snow covered the ground continuously from about mid-December to midMarch, whereas in the winter of 1982-83 there was only occasional and short-lived snow cover. Summer precipitation was similar in each of the two observational years, except for intense late summer precipitation in 1982. The daily SAT record, shown between Figures $1 \mathrm{a}$ and $1 \mathrm{~b}$, ranges between about -30 to $+29^{\circ} \mathrm{C}$ in $1981-82$, and between -21 and $+29^{\circ} \mathrm{C}$ in $1982-83$. Observed subsurface temperatures appear in Figure 1b; despite the mete- 


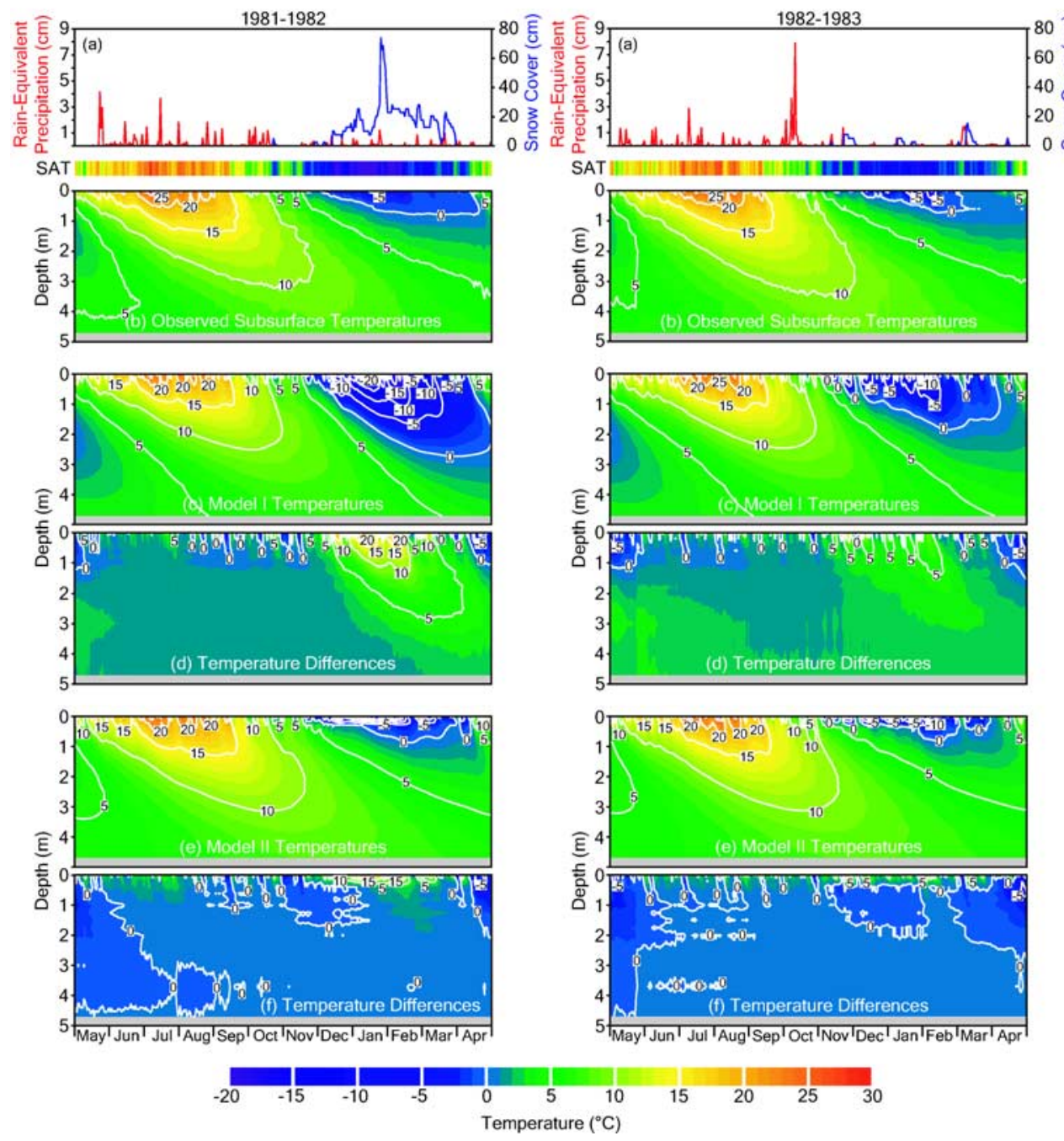

Figure 1. Meteorological variables and observed and modeled subsurface temperatures at Fargo, North Dakota during 1981-82 and 1982-83: (a) observed precipitation and snow cover; (b) observed subsurface temperatures; SAT is shown between (a) and (b); (c) subsurface temperatures computed from Model I (uniform diffusivity); (d) difference between observed subsurface temperatures and the Model I results (b minus c); (e) subsurface temperatures computed from Model II (time-dependent diffusivity); and (f) difference between observed subsurface temperatures and the Model II results (b minus e). Left and right columns represent the two observational years, 1981-82 and 1982-83, respectively.

orological differences in the respective winters, the subsurface temperature fields are remarkably similar. Each shows a 'tongue' of warm summer temperatures propagating downward with time, and a more subdued and confined zone of cold winter temperatures. The confinement of sub-zero winter temperatures to the upper meter of the subsurface is a result of both snow insulation and latent heat effects.

[13] Figure 1c displays subsurface temperatures computed from Model I (uniform diffusivity). Because Model I includes no seasonal insulating or latent heat effects, it produces downward-propagating 'tongues' of seasonal temperatures in both summer and winter. Figure 1d displays the difference between the observed subsurface temperatures and the Model I results (Figure $1 \mathrm{~b}$ minus Figure 1c). The principal failure of the Model I temperatures appears in the winter of both years, where the observations show a subdued winter signature in the subsurface and the model produces a cold 'tongue' at depth. As noted above, the RMS difference between observations and Model I calculations is greater than $2.7^{\circ} \mathrm{C}$ in both years.

[14] Figure 1e displays subsurface temperatures computed from Model II (time-dependent diffusivity). These model temperatures are much more similar to the observed temperatures. In particular, the model temperatures show the subdued and confined winter temperatures that appear in the observations, in contrast to the well-developed downward-propagating 'tongue' of summer temperatures. The difference between the observed subsurface temperatures and the Model II results (Figure 1b minus Figure 1e) are shown in Figure 1f; these differences are substantially smaller than those shown in Figure 1d, with an RMS difference of about $0.5^{\circ} \mathrm{C}$ in both years. It is clear that the Model II temperatures compare much better with the 


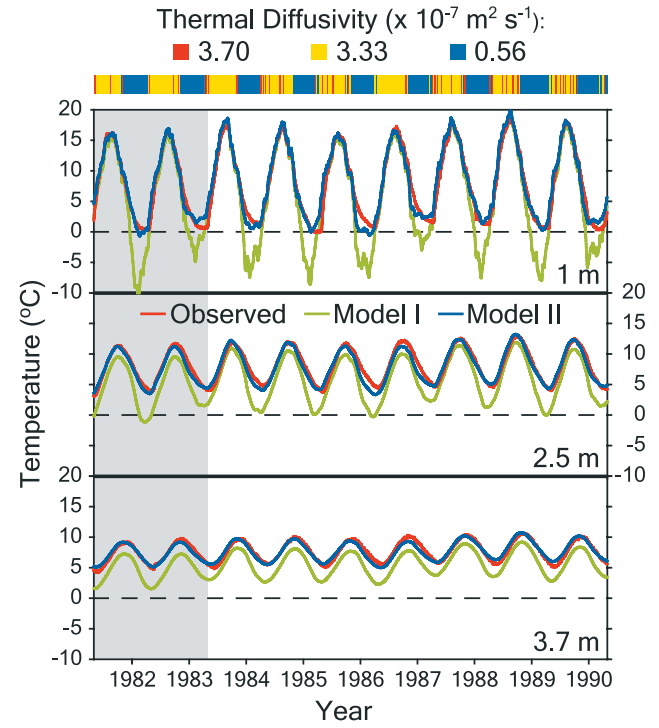

Figure 2. Observed and modeled temperatures at depths of $1.0,2.5$ and $3.7 \mathrm{~m}$. Shaded years are tuning years, unshaded years are validation years. Time-dependent thermal diffusivity used in Model II shown in color bar at top.

observations, both qualitatively and quantitatively, than the Model I temperatures.

\section{Validation}

[15] We next undertake a validation of this tuned Model II by using it to compute subsurface temperatures for seven subsequent years beyond the tuning interval, and comparing these computed temperatures with observations. In Figure 2 we show observed and modeled temperatures at three specific depths over the full nine-year tuning and validating interval. Again, it is clear that the tuned Model II calculations are superior to those resulting from Model I, in terms of comparison to observations. The Model II RMS errors at $1.0,2.5$ and $3.7 \mathrm{~m}$ depth are $1.26,0.75$ and $0.50^{\circ} \mathrm{C}$, respectively, whereas the Model I errors at those same depths are $3.55,2.75$, and $2.22^{\circ} \mathrm{C}$, respectively. The RMS error over all depths $\geq 1 \mathrm{~m}$ over the full nine-year interval for Models I and II are 2.87 and $0.83^{\circ} \mathrm{C}$, respectively, a factor of 3.5 performance enhancement by Model II.

\section{Conclusions}

[16] The effects of meteorological conditions on subsurface temperatures can be effectively captured using a layerover-half-space conductive model in which the thermal diffusivity of the layer changes according to surface air temperature, precipitation (rain or snow) and snow cover. Such a model matches observed subsurface temperatures significantly better than a conductive model with uniform thermal diffusivity. This parameterization of the coupling between air and ground temperatures contrasts in its simplicity to more complex land-surface process models, and provides a strategy for investigating the consequences of long-term trends in SAT, precipitation and snow cover on subsurface temperatures. Meteorological variables have been observed and archived for much longer periods and with much greater regional coverage than have subsurface temperature observations. With this simple representation of meteorological effects one can numerically simulate subsurface temperatures over the entire archival period, and therefore investigate the long-term character and fidelity of SAT-GST coupling.

[17] Acknowledgments. We thank John Enz, State Climatologist of North Dakota, for providing the Fargo temperature records used in this investigation. This research was supported in part by NSF award ATM-0081864, NASA grant GWEC 00000132 , and by the University of Michigan through grant OVPR-4237.

\section{References}

Baker, J. M., and D. G. Baker (2002), Long-term ground heat flux and heat storage at a mid-latitude site, Clim. Change, 54, 295-303.

Bartlett, M. G., D. S. Chapman, and R. N. Harris (2004), Snow and the ground temperature record of climate change, J. Geophys. Res., 109, F04008, doi:10.1029/2004JF000224.

Brown, P., A. Hindmarsh, and L. R. Petzold (1994), Using krylov methods in the solution of large-scale differential-algebraic equations, SIAM J. Sci. Comput., 15, 1467-1488.

Chapman, D. S., M. G. Bartlett, and R. N. Harris (2004), Comment on "Ground vs. surface air temperature trends: Implications for borehole temperature reconstructions" by Mann and Schmidt, Geophys. Res. Lett., 31, L07205, doi:10.1029/2003GL019054.

González-Rouco, F., H. von Storch, and E. Zorita (2003), Deep soil temperature as proxy for surface air-temperature in a coupled model simulation of the last thousand years, Geophys. Res. Lett., 30(21), 2116, doi:10.1029/2003GL018264.

Grundstein, A., P. Todhunter, and T. Mote (2005), Snowpack control over the thermal offset of air and soil temperatures in eastern North Dakota, Geophys. Res. Lett., 32, L08503, doi:10.1029/2005GL022532.

Hinkel, K. M., and F. E. Nelson (2003), Spatial and temporal patterns of active layer thickness at Circumpolar Active Layer Monitoring (CALM) sites in northern Alaska, 1995-2000, J. Geophys. Res., 108(D2), 8168, doi:10.1029/2001JD000927.

Mann, M. E., and G. Schmidt (2003), Ground vs. surface air temperature trends: Implications for borehole surface temperature reconstructions, Geophys. Res. Lett., 30(12), 1607, doi:10.1029/2003GL017170.

Osterkamp, T. E. (2002), Establishing long-term permafrost observatories for active-layer and permafrost investigations in Alaska: 1977-2000, Permafrost Periglacial Processes, 14(4), 331-342.

Pollack, H. N., and J. Smerdon (2004), Borehole climate reconstructions: Spatial structure and hemispheric averages, J. Geophys. Res., 109, D11106, doi:10.1029/2003JD004163.

Schmidt, W. L., W. D. Gosnold, and J. W. Enz (2001), A decade of air-ground temperature exchange from Fargo, North Dakota, Global Planet. Change, 29, 311-325.

Smerdon, J. E., H. N. Pollack, J. W. Enz, and M. J. Lewis (2003), Conduction-dominated heat transport of the annual signal in soil, J. Geophys. Res., 108(B9), 2431, doi:10.1029/2002JB002351.

Smerdon, J. E., H. N. Pollack, V. Cermak, J. W. Enz, M. Kresl, J. Safanda, and J. F. Wehmiller (2004), Air-ground temperature coupling and subsurface propagation of annual temperature signals, J. Geophys. Res., 109, D21107, doi:10.1029/2004JD005056.

Sokratov, S. A., and R. G. Barry (2002), Intraseasonal variation in the thermoinsulation effect of snow cover on soil temperature and energy balance, J. Geophys. Res., 107(D10), 4093, doi:10.1029/2001JD000489.

Stieglitz, M., S. J. Dery, V. E. Romanovsky, and T. E. Osterkamp (2003), The role of snow cover in the warming of arctic permafrost, Geophys. Res. Lett., 30(13), 1721, doi:10.1029/2003GL017337.

van Keken, P. E., D. A. Yuen, and L. R. Petzold (1995), DASPK: A new high order and adaptive time-integration technique with applications to mantle convection with strongly temperature- and pressure-dependent rheology, Geophys. Astrophys. Fluid Dyn., 80, 57-74

Zhang, T., R. G. Barry, D. Gilichinsky, S. S. Bykhovets, V. A. Sorokovikov, and J. Ye (2001), An amplified signal of climatic change in soil temperatures during the last century at Irkutsk, Russia, Clim. Change, 49, 41-76.

H. N. Pollack, J. E. Smerdon, and P. E. van Keken, Department of Geological Sciences, University of Michigan, Ann Arbor, MI 48109-1005, USA. (hpollack@umich.edu) 